\title{
Transaction
}

\section{Consideration of Solvent Effect on Precipitation Polymerization of Poly(ether-ketone)s via Friedel-Craft Acylation}

\author{
Manabu Ohmori ${ }^{* 1}$, Kunio Kimura ${ }^{* 1}$, Yuhiko Yamashita ${ }^{* 1,}$ and Yoshimitsu Sakaguchi ${ }^{* 2}$ \\ ${ }^{* 1}$ Faculty of Environmental Science and Technology, Okayama University, \\ 3-1-1 Tsushima-naka, Okayama 700-8530, Japan \\ ${ }^{* 2}$ Toyobo Co., Ltd., Research Center, 1-1 Katata 2-Chome, Ohtsu, Shiga 520-0292, Japan
}

\begin{abstract}
Precipitation polymerization of diphenyl ether and isophthaloyl chloride catalyzed by $\mathrm{AlCl}_{3}$ via Friedel-Crafts acylation was examined in various solvents to clarify the polymerization behavior. Polymerizations were carried out in three categorized solvents based on the solubility to both catalyst and polymer, which were cyclohexane (CH), 1,2-dichloroethane (DCE) and DCE containing $2 \mathrm{wt} \%$ nitrobenzene (2\%-NB). In DCE which was widely used, the oligomers were precipitated as a form of the complex with $\mathrm{AlCl}_{3}$ at the early stage of polymerization. The precipitates of the oligomers were swollen by the solvent, in which any short-range regular structure did not exist. The further polymerization proceeded even in the precipitates with eliminating by-produced $\mathrm{HCl}$, and high molecular weight poly(ether-ketone)s (PEK) were finally formed. Nevertheless the reaction in 2\%-NB yielded the well-swollen precipitates, the high molecular weight PEK was not synthesized in the precipitates because the reaction was terminated by not only the inefficient elimination of $\mathrm{HCl}$ due to the higher solubility of $\mathrm{HCl}$ but also the deactivation of catalyst by coordination of $\mathrm{NB}$ to $\mathrm{AlCl}_{3}$. Although the precipitation occurred more readily in $\mathrm{CH}$ due to the lower solubility of oligomers, the polymer was not synthesized in the precipitates. The resulting precipitates comprised of the dimers were not swollen in this case, and thereby it was very difficult to react between dimers and eliminate $\mathrm{HCl}$ from the precipitates. The solvents having high miscibility to catalyst and the polymers, low solubility of $\mathrm{HCl}$ gas, and no basicity are necessary for making high molecular weight polymers via the precipitation polymerization.
\end{abstract}

(Received December 10, 2005 ; Accepted February 4, 2006)

\section{Introduction}

Poly(ether-ketone)s (PEK) belong to a class of high performance materials that are known because of their excellent thermal stability, good mechanical properties and environmental. Preparations of PEKs are classified into two methods; the aromatic nucleophilic substitution and the aromatic electrophilic substitution, so-called Friedel-Crafts acylation catalyzed by aluminum trichloride $\left(\mathrm{AlCl}_{3}\right)$ [1]. In the latter case, the reaction gives a precipitate of the complex of oligomer and catalyst in the course of polymerization [2-6]. It has been revealed that even though the oligomer is precipitated, the molecular weight of PEK increases with reaction time in the precipitates formed in 1,2-dichloroethane (DCE) [3,5,7]. Since it is generally thought that precipitation terminates chain growth, the increase of molecular weight after precipitation is very interesting phenomenon. It has also been reported that the polymerization medium greatly affects the molecular weight of the resulting PEK, and DCE is a good solvent to prepare the high molecular weight PEK [8]. However, further details of the solvent effect on the precipitation polymerization have not been clarified so far, and few considerations were performed on the polymerization behavior of the precipitation polymerization from the view of the morphology and the structure of the precipitates to our knowledge.

This paper aims to clarify the precipitation polymerization behavior of diphenyl ether (DPE) and isophthaloyl chloride (IPC) catalyzed by $\mathrm{AlCl}_{3}$ on the basis of the consideration of the solvent effect.

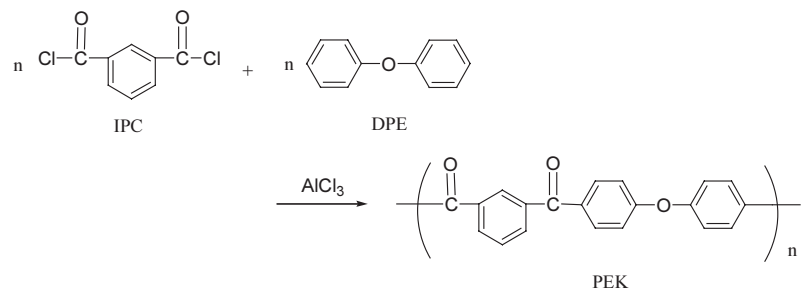




\section{Experimental}

\subsection{Materials}

IPC (Aldrich Co. Ltd.) was purified by sublimation under vacuum. DPE (Tokyo Kasei Kogyo Co. Ltd.) and NB (Ishizu Seiyaku Ltd.) were distilled under vacuum. DCE (Ishizu Seiyaku Ltd.) and cyclohexane (CH, Ishizu Seiyaku Ltd.) were distilled over calcium hydrate. $\mathrm{AlCl}_{3}$ (Aldrich Co. Ltd.) was used as purchased.

\subsection{Polymerization}

The precipitation polymerization of PEK in DCE is described as a typical example. In a $100 \mathrm{ml}$ of four-necked flask equipped with a nitrogen inlet tube and a mechanical stirrer, $0.84 \mathrm{~g}$ of DPE $(4.93 \mathrm{mmol})$ and $1.00 \mathrm{~g}$ of IPC $(4.93 \mathrm{mmol})$ were dissolved in $14 \mathrm{ml}$ of dried DCE. After the solution was cooled below $5^{\circ} \mathrm{C}$ in an ice bath, $1.71 \mathrm{~g}$ of $\mathrm{AlCl}_{3}(12.8 \mathrm{mmol})$ was added, and the reaction mixture was stirred for 1 hour. Thereafter, the reaction was continued at $25^{\circ} \mathrm{C}$ for 20 hours. The polymer precipitates and the solution were separated by filtration. The filtrate was poured into methanol and the precipitates were collected as the compounds dissolved in solution. Both the polymer precipitates and the compounds recovered from the solution were washed by methanol using Soxhlet extractor for 20 hours, and dried under vacuum overnight at $30^{\circ} \mathrm{C}$.

\subsection{Measurements}

${ }^{1} \mathrm{H}-\mathrm{NMR}$ spectra were obtained on Varian Unity-500 spectrometer in a mixture of $\mathrm{CDCl}_{3}$ and trifluoroacetic acid at room temperature. Wide-angle X-ray scattering (WAXS) was conducted on Rigaku-2013 diffractometer with nickel-filtered $\mathrm{CuK} \alpha$ radiation $(35 \mathrm{kV}, 20 \mathrm{~mA})$. Degree of swelling of the precipitate (Ds) was evaluated using Perkin-Elmer TGA7 thermogravimetric analyzer with the heating rate of $10^{\circ} \mathrm{C} \cdot \mathrm{min}^{-1}$ in nitrogen atmosphere. The reaction was monitored by the titration of generated $\mathrm{HCl}$ gas with $0.1 \mathrm{~mol} \cdot \mathrm{L}^{-1}$ sodium hydroxide solution.

\section{Results and Discussion}

\subsection{Influence of solvent on polymerization}

Polymerizations were carried out in three categorized solvents. DCE is a common polymerization solvent which does not dissolve $\mathrm{AlCl}_{3}$ but dissolves IPC- $\mathrm{AlCl}_{3}$ complex. $\mathrm{NB}$ is a good solvent for both $\mathrm{AlCl}_{3}$ and IPC- $\mathrm{AlCl}_{3}$ complex [9]. $\mathrm{CH}$ is a poor solvent for them. The polymerization results in these solvents are summarized in Table 1. ${ }^{1} \mathrm{H}-\mathrm{NMR}$ spectra of the precipitates are illustrated in Fig. 1 and signals can be
Table 1 Results of precipitation polymerization in several solvents ${ }^{\mathrm{a}}$

\begin{tabular}{|c|c|c|c|c|}
\hline \multirow{2}{*}{ Solvent ${ }^{b}$} & \multicolumn{2}{|c|}{ Precipitate } & \multicolumn{2}{|c|}{$\begin{array}{l}\text { Oligomer recovered } \\
\text { from solution }^{\mathrm{c}}\end{array}$} \\
\hline & $\begin{array}{l}\text { Yield } \\
(\%)\end{array}$ & $\operatorname{DPn}^{\mathrm{d}}$ & $\begin{array}{l}\text { Recovery } \\
\text { yield (\%) }\end{array}$ & $\mathrm{DPn}^{\mathrm{d}}$ \\
\hline DCE & 99.4 & 50.0 & 0.5 & - \\
\hline NB & 0 & - & 42.7 & 3.9 \\
\hline $\mathrm{CH}$ & 11.7 & 2.0 & 0 & - \\
\hline
\end{tabular}

${ }^{a}$ Polymerizations were carried out for 20 hours.

${ }^{\mathrm{b}}$ DCE : 1,2-dichloroethane, NB : nitronbenzene, 2\%

$\mathrm{NB}$ : DCE containing $2 \mathrm{wt} \% \mathrm{NB}, \mathrm{CH}$ : cyclohexane

${ }^{c}$ obtained by evaporation of the solvent and washed with methanol.

d estimated by the NMR end-group analysis.

${ }^{\mathrm{e}}$ not measured.

Table 2 Polymerization results in mixed solvent of NB and DCE

\begin{tabular}{cccccc}
\hline \multirow{2}{*}{$\begin{array}{c}\text { Mixing } \\
\text { ratio of NB } \\
(\mathrm{wt} \%)^{\mathrm{a}}\end{array}$} & \multicolumn{2}{c}{ Precipitate } & & \multicolumn{2}{c}{$\begin{array}{c}\text { Oligomer dissolved } \\
\text { in solution }\end{array}$} \\
\cline { 5 - 6 } \cline { 5 - 6 } & $\begin{array}{c}\text { Yield } \\
(\%)\end{array}$ & $\mathrm{DPn}^{\mathrm{c}}$ & & $\begin{array}{c}\text { Recovery } \\
\text { yield (\%) }\end{array}$ & $\mathrm{DPn}^{\mathrm{c}}$ \\
\hline 80 & 0 & - & & 50.6 & 4.7 \\
50 & 0 & - & & 50.0 & 3.1 \\
25 & 0 & - & & 55.7 & 3.9 \\
5 & 0 & - & & 84.4 & 5.5 \\
2 & 86.7 & 18.0 & & 9.6 & 7.0 \\
\hline
\end{tabular}

${ }^{\mathrm{a}}$ Mixing ratio of $\mathrm{NB}=\{\mathrm{NB} w \mathrm{wt} /[(\mathrm{NB} w \mathrm{t}+\mathrm{DCE} \mathrm{wt})]\} \mathrm{x}$ 100

${ }^{\mathrm{b}}$ obtained by evaporation of the solvent and washed with methanol.

' estimated by the NMR end-group analysis.

assigned according to the previous report [7]. The number average degree of polymerization (DPn) was estimated with the content of end-groups. DCE afforded the precipitates of PEK with the yield of $99.4 \%$, of which the DPn was 50. Contrary to DCE, the precipitation did not occur in NB and the reaction proceeded in homogeneous solution. The compounds were recovered from the solution with the yield of $42.7 \%$ and they were the oligomers of which the DPn was 3.9. This implies that the oligomers to be precipitated cannot be formed in NB. The polymerizations were carried out in the mixed solvent of NB and DCE to induce the precipitation with the mixing ratio of NB varying from 80 to $2 \mathrm{wt} \%$. The polymerization results are summarized in Table 2 . When the content of NB was more than $2 \mathrm{wt} \%$, the reactions proceeded in homogeneous solution and only 

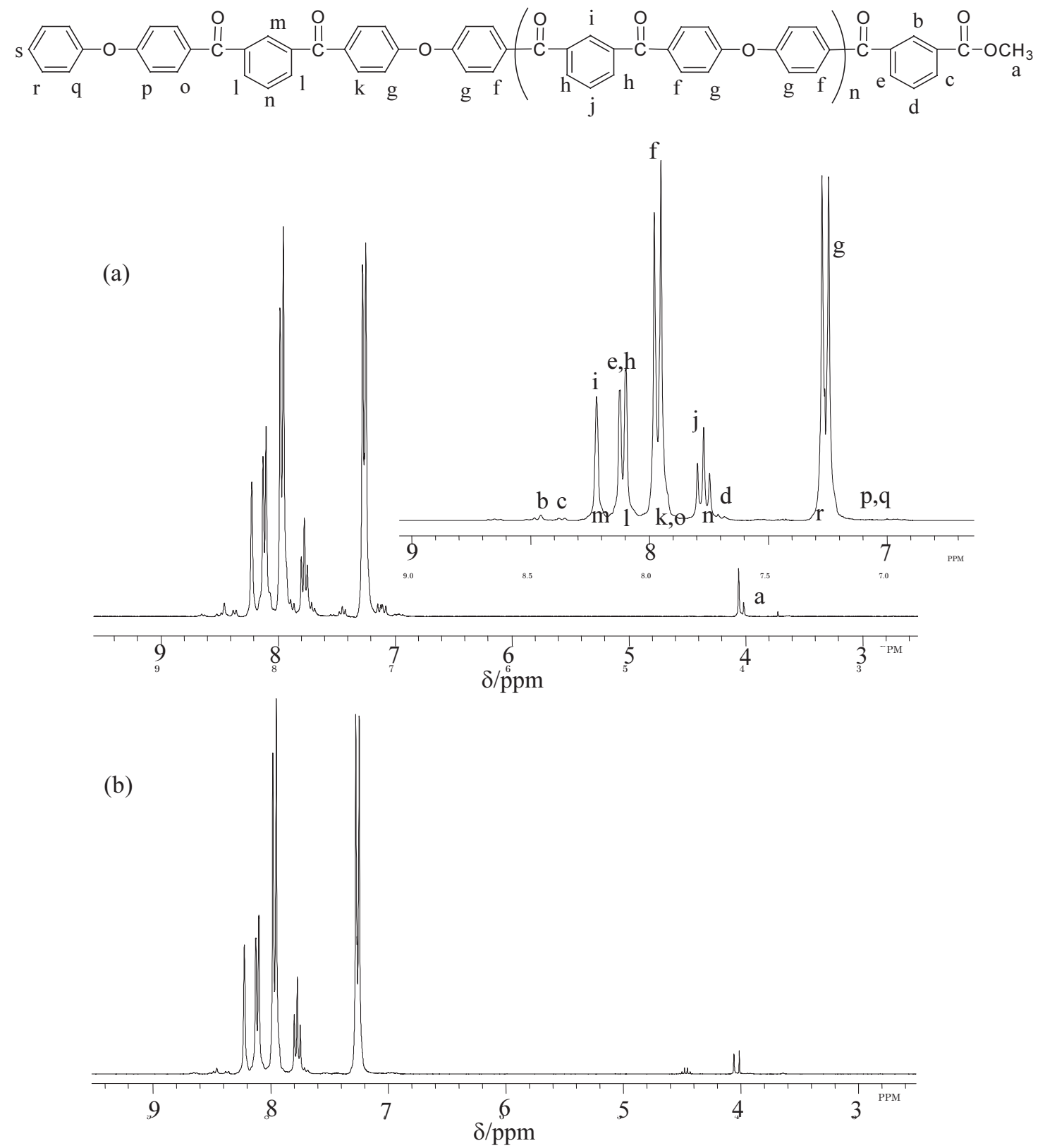

(c)

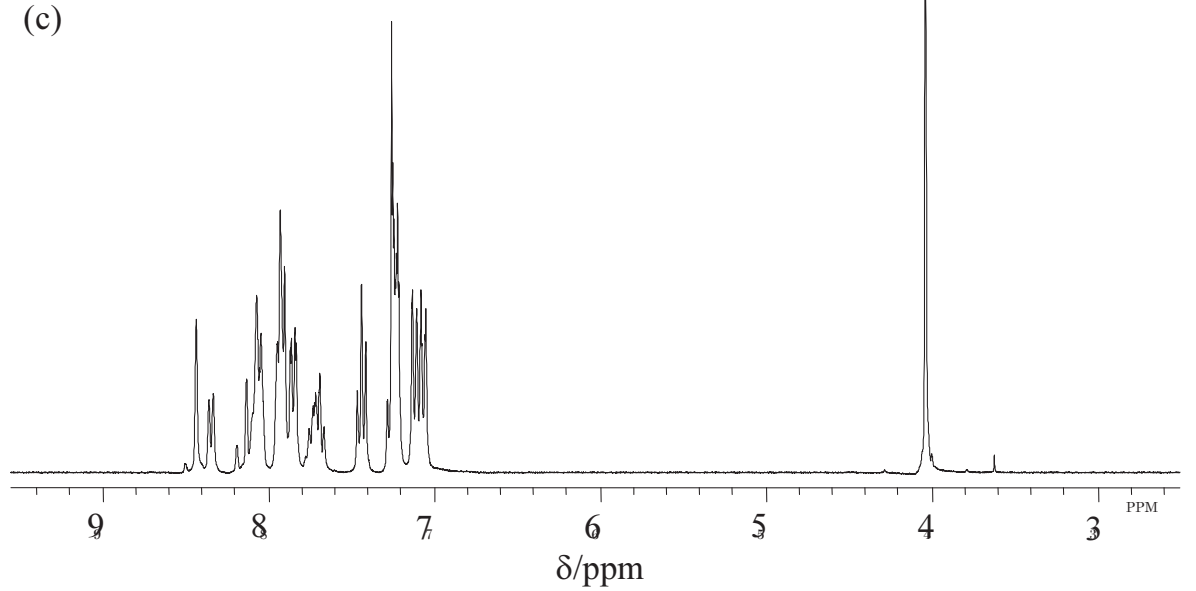

Fig. $1{ }^{1} \mathrm{H}-\mathrm{NMR}$ spectra of precipitates prepared in (a) DCE, (b) 2\%-NB and (c) $\mathrm{CH}$. 
low molecular weight oligomers were formed as well as in NB. The precipitation occurred in DCE containing $2 \mathrm{wt} \%$ of $\mathrm{NB}(2 \%-\mathrm{NB})$ and the precipitates were obtained with the yield of $86.7 \%$, of which the DPn was 18 . Though the DPn of the precipitates was higher than that of the oligomers formed in NB, it was much lower than that in DCE. The DPn of the oligomers recovered from the solution of $2 \%$-NB was 7.0 and it was slightly higher than that in NB. In $\mathrm{CH}$, the precipitates were obtained with the yield of $11.7 \%$, of which the DPn was 2.0. The precipitates were comprised of dimers. Despite the precipitates are formed in the solvents of DCE, $2 \% \mathrm{NB}$ and $\mathrm{CH}$, the high molecular weight polymer can be formed only in DCE.

The structure of the as formed precipitates is examined by WAXS. The samples for measurements contained the solvent and catalyst. Fig. 2 shows WAXS profiles of the precipitates prepared in DCE (PDCE) and $\mathrm{CH}(\mathrm{PCH})$. WAXS of the precipitates prepared in $2 \%$-NB (P2\%-NB) could not be measured because they were very jellylike. WAXS profile of PEK purified by washing with methanol is also shown in Fig. 2. The profiles of the as formed precipitates are completely different from that of the purified PEK. The characteristic diffraction peaks of the purified polymer appeared at $2 \theta$ of $18^{\circ}, 23^{\circ}$ and $28^{\circ}$ are not observed in the pattern of the as formed precipitates. Diffuse halo attributed to amorphous region is not detected. The characteristic peaks appeared in the profiles of the as formed precipitates can be accounted for according to the unit cell of $\mathrm{AlCl}_{3}$ crystal [10] as illustrated in Fig. 2. This fact indicates that the precipitates do not possess any short-range regular structures.

The morphology of the as formed precipitates was observed on SEM as shown in Fig. 3. The samples for observation were the precipitates washed with methanol and dried. The precipitates do not exhibit crystal habit and the sizes of them are not uniform. Porous structures are clearly observed in PDCE and P2\%-NB. The average pore size of $\mathrm{P} 2 \%-\mathrm{NB}$ is bigger than that of $\mathrm{PDCE}$, and the maximum pore sizes are ca. $15 \mu \mathrm{m}$ and ca. $5 \mu \mathrm{m}$, respectively. These pores are seen as continuous pores. In contrast, the porous structure is not observed in $\mathrm{PCH}$. While these porous structures might be formed during the evaporation of the solvents, these morphological features show that P2\%-NB and PDCE are highly swollen by the solvents compared with PCH. In order to grasp the swollen state of the precipitates quantitatively, the value of Ds of the as formed precipitates was measured on TGA. The weight loss at the boiling point of the solvent

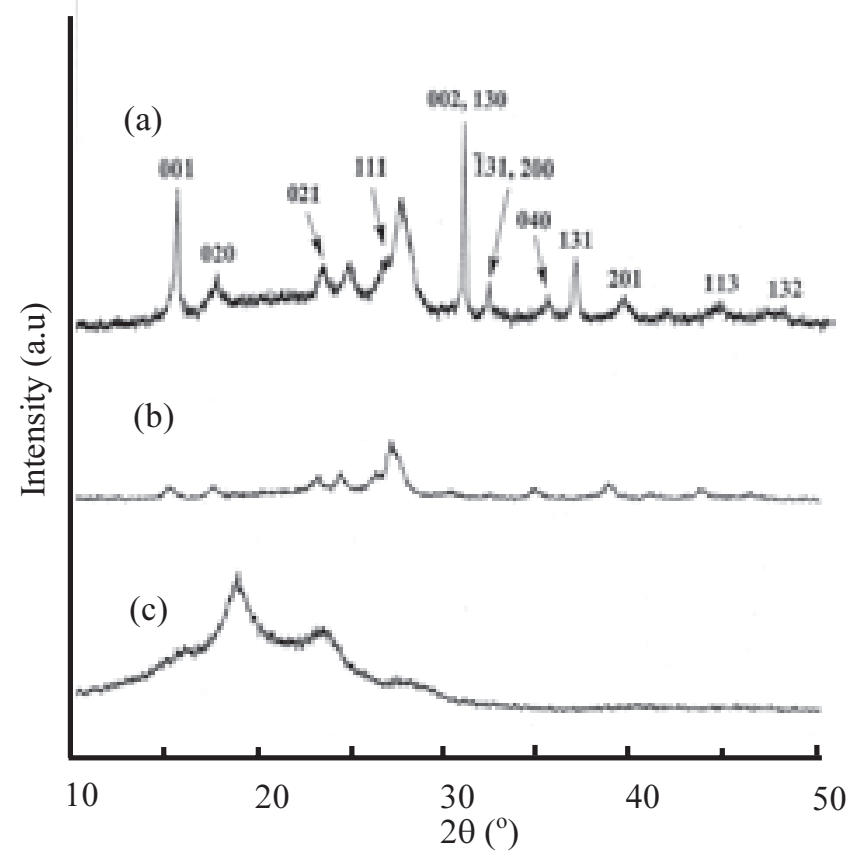

Fig. 2 WAXS profiles of (a) as formed PEK prepared in $\mathrm{CH}$, (b) as formed and (c) purified PEK prepared in DCE. Peaks in (a) are indexed according to the crystal unit cell of $\mathrm{AlCl}_{3}$.

is the content of the solvent regarding as Ds. Fig. 4 shows the TGA profiles of the as formed precipitates. The values of Ds are highly related to the solvents. PCH shows the lowest Ds of 3\%. The Ds of PDCE and $\mathrm{P} 2 \%-\mathrm{NB}$ are $52 \%$ and $72 \%$, respectively. The Ds is in good agreement with the morphology of the precipitates. $\mathrm{PCH}$ is the densest precipitates in which the dimers aggregate tightly. On the other hand, $\mathrm{P} 2 \%-\mathrm{NB}$ and PDCE are significantly well swollen and they are physical gels rather than solid precipitates. It is likely that the swollen state of the precipitated gel influences the polymerization.

\subsection{Mechanism of precipitation polymerization}

The polymerization time dependencies of the yield and the DPn of both the precipitates and the compounds recovered from the solution were examined in DCE, $2 \%-\mathrm{NB}$ and $\mathrm{CH}$ to clarify the mechanism of the precipitation polymerization as shown in Fig. 5. Fig. 6 is the plot of average number of polymer chains in the precipitates $(N p)$ calculated with the yield and DPn as a function of the polymerization time. With respect to the polymerization in DCE, the yield of PDCE increases with time corresponding to the decrease of the oligomers recovered from the solution. The DPn of PDCE increases with time and it reaches 50 at 2 hours, whereas the DPn of the recovered oligomer is constant at ca. 5 throughout the polymerization. These results reveal that the oligomers of which the DPn exceeds ca. 5 are 

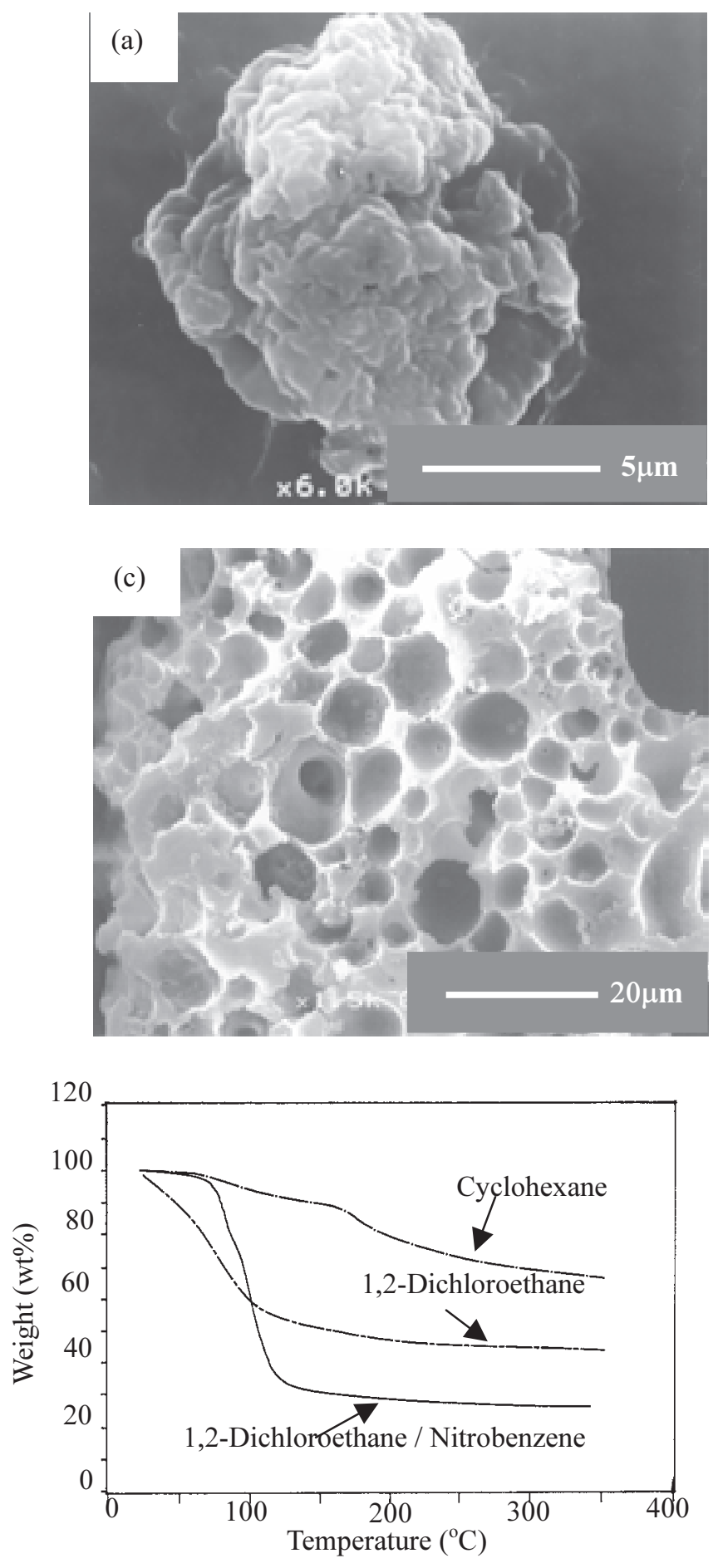

Fig. 4 TGA traces of as formed PEK polymerized in various solvents.

precipitated and the polymerization proceeds in the precipitates. The $N p$ increases with the yield until 1 hour due to the precipitation of the oligomers. During this stage, the DPn of PDCE increases slightly from 9.5 to 10.5 . Then the $N p$ decreases oppositely with the increase of both the yield and the DPn from 1 hour to 2.5 hours. This decrease of the $N p$ and the increase of the yield reveal the further polymerization between polymers

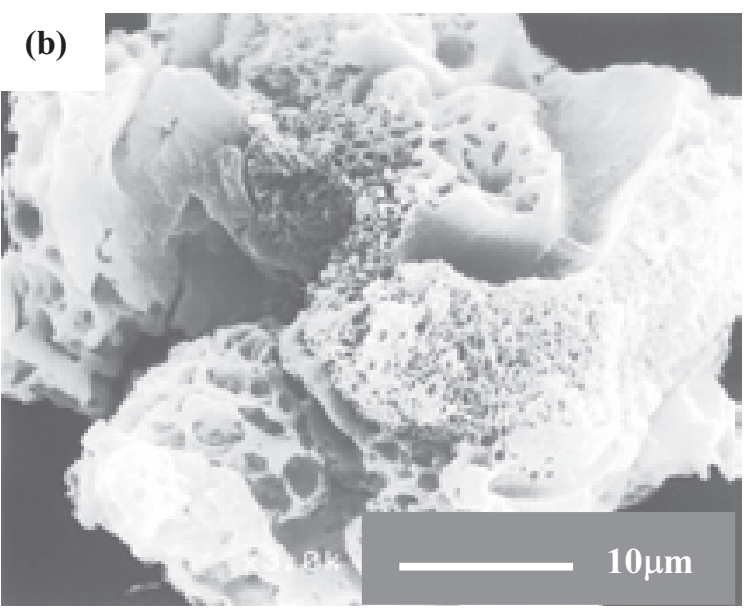

Fig. 3 Morphology of PEK precipitates prepared in (a) $\mathrm{CH}$, (b) DCE and (c) 2\%-NB.

in the precipitates. Finally the $N p$, the yield and the DPn become constant after 2.5 hours, and the polymerization in the precipitates does not proceed. Fig. 7 is a plot of Ds of PDCE as a function of polymerization time. The Ds of the precipitates formed within 1 hour is ca. $70 \%$ and the precipitates are highly swollen at the early stage of polymerization. The Ds decreases gradually with time due to the increase of the molecular weight of polymers, which brings about to lower the miscibility of polymers and solvent, and then it levels off to ca. $52 \%$ after 4 hours. These results imply that the polymer molecules possess enough mobility to react at the early stage of polymerization and they lose it after 4 hours leading to the termination of the polymerization in the precipitates. With respect to the polymerization in $2 \%$-NB, the precipitation occurs after ca. 7 hours and the yield of the precipitates increases rapidly within 1 hour after the start of the precipitation. The DPn of P2\%-NB increases very slightly from 13 to 18 with time. The DPn of the oligomers recovered from the solution increases from 8 to 11 up to 6 hours and then it decreases to 7 after the precipitation starts because the oligomers having higher DPn are precipitated from the solution. The $N p$ increases until 12 hours, and then decreases until 16 hours. The decrement of the $N p$ of $\mathrm{P} 2 \%-\mathrm{NB}$ is 

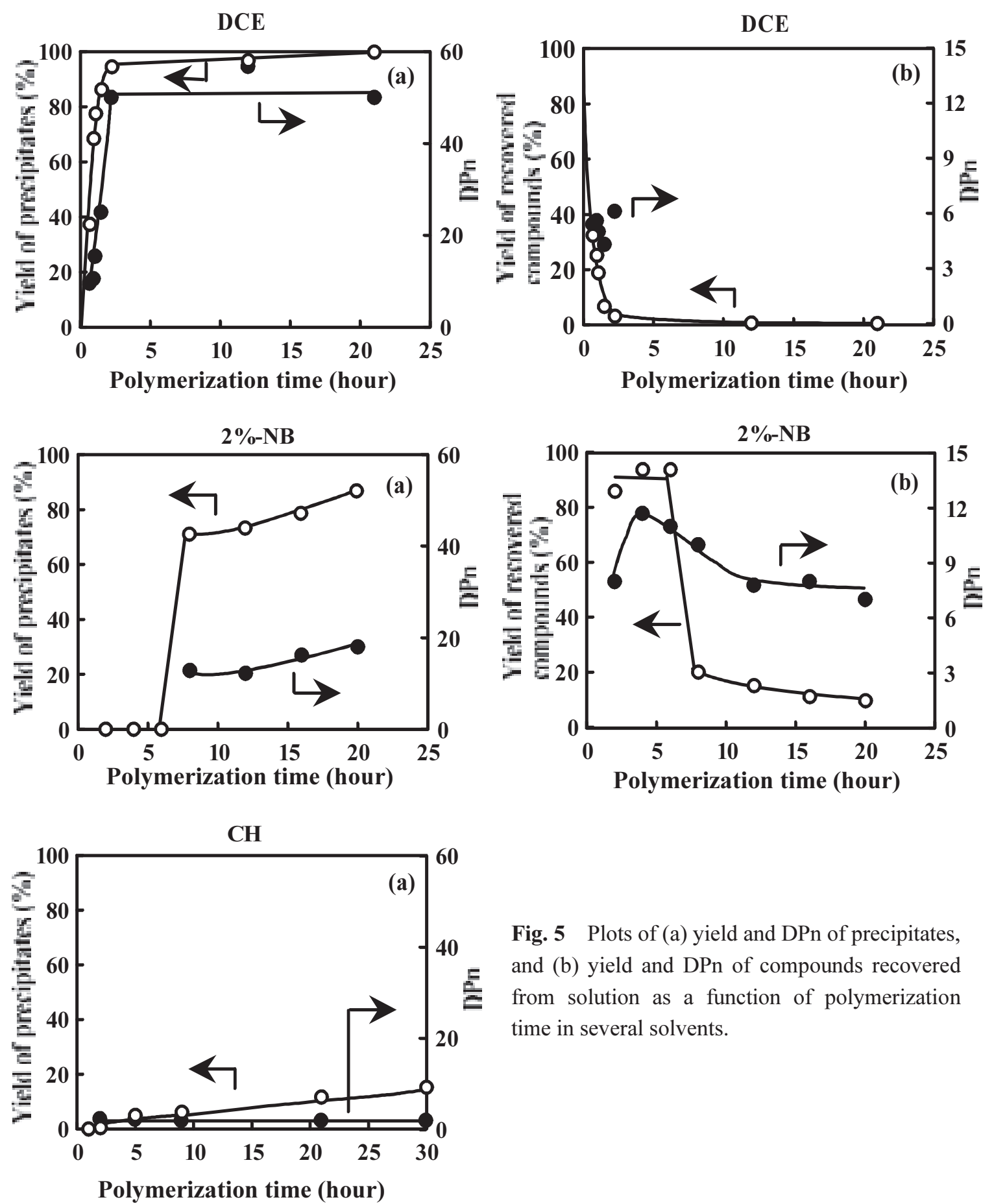

Fig. 5 Plots of (a) yield and DPn of precipitates, and (b) yield and DPn of compounds recovered from solution as a function of polymerization time in several solvents.

smaller than that of PDCE. This result suggests that the further polymerization between the polymers in the precipitates occurs as well as in DCE, but it does not proceed so effectively compared with DCE. With respect to the reaction in $\mathrm{CH}$, the precipitation started at 2 hours. Although the yield of $\mathrm{PCH}$ is very low, it increases with time. The DPn of PCH is ca. 2, which is lower than that of the oligomers recovered from $2 \%$-NB and DCE, and it does not increase throughout the polymerization. The compounds dissolved in the solution were not collected because the molecular weight was too low to be precipitated in methanol. The $N p$ of $\mathrm{PCH}$ increases continuously with time and linearly with

the yield. These indicate that the dimers are precipitated but the further polymerization does not occur in them.

It had been reported that Friedel-Crafts acylation reaction is a reversible reaction and the elimination of by-produced $\mathrm{HCl}$ is necessary to move the equilibrium toward the product site [11]. We had reported that the replacement of the solvent to the fresh one accelerated the Friedel-Crafts acylation catalyzed by $\mathrm{AlCl}_{3}$ and higher molecular weight PEK could be obtained [3]. This result proves that effective elimination of $\mathrm{HCl}$ was of great advantage to synthesize high molecular weight PEK. Mole fraction solubility of $\mathrm{HCl}$ gas at $25^{\circ} \mathrm{C}$ in $\mathrm{NB}$, DCE and $\mathrm{CH}$ had been reported as $0.063,0.037$ and 0.015 [12]. 

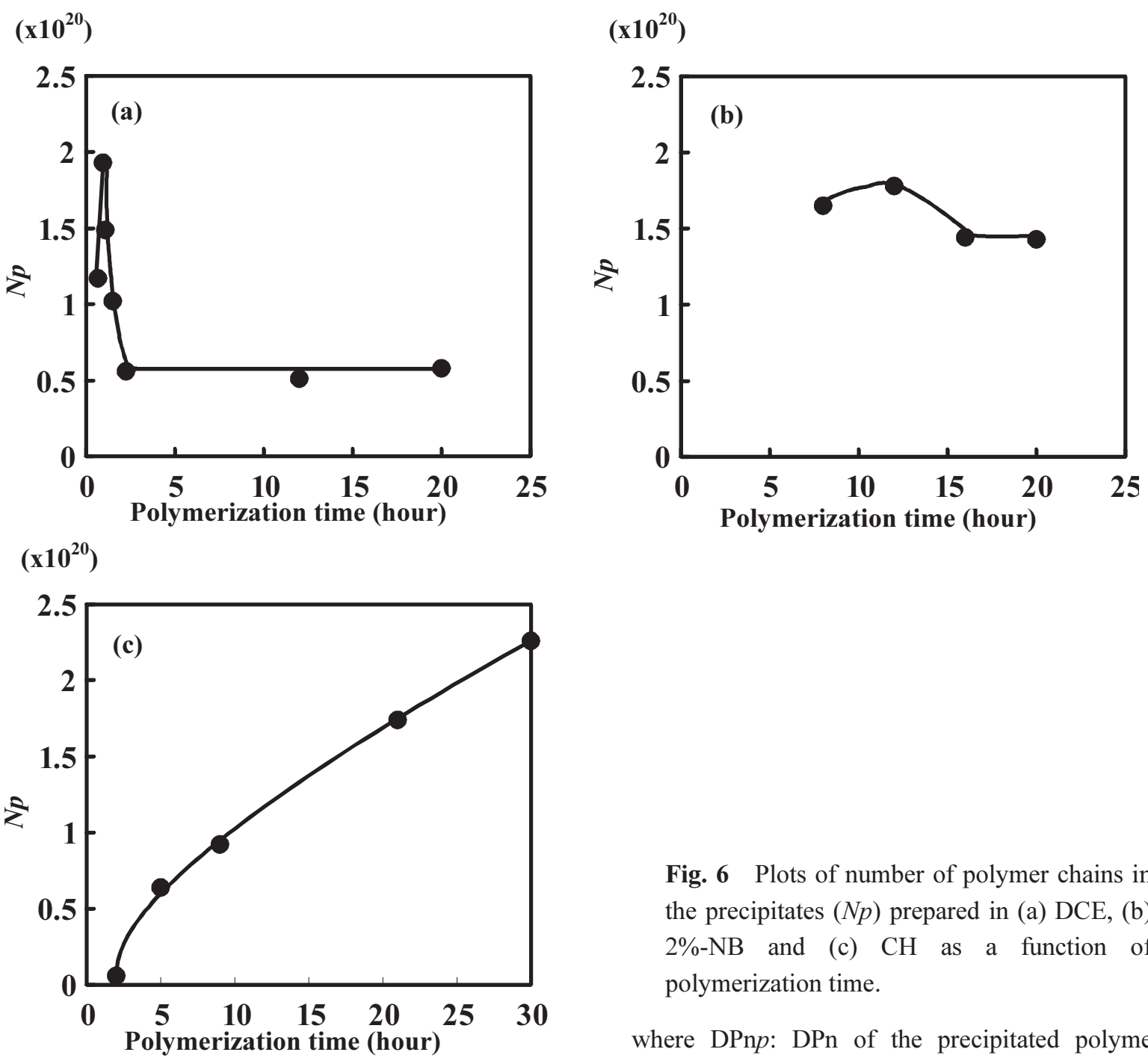

These data strongly suggests that the elimination of $\mathrm{HCl}$ is related to the solvents. $\mathrm{HCl}$ gas evolved by the reaction was quantitatively monitored by the titration with aq. $\mathrm{NaOH}$ to follow the reaction. Fig. 8 is the plot of the extent of reaction calculated with the titration results $\left(p_{\mathrm{HCl}}\right)$ as a function of polymerization time. In every reaction, $p_{\mathrm{HCl}}$ increase at the early stage and then they become saturated. The polymerization in DCE gives the maximum $p_{\mathrm{HCl}}$ of 1.10 at 8 hours, which is over 1.0 due to the generation of $\mathrm{HCl}$ gas caused by a hydrolysis of $\mathrm{AlCl}_{3} . \quad 2 \%-\mathrm{NB}$ and $\mathrm{CH}$ give the $p_{\mathrm{HCl}}$ of 0.34 and 0.36 at 8 hours, respectively. The extent of reaction estimated with average DPn in the products (DPnav) by the following equations $\left(p_{\mathrm{DPn}}\right)$ are compared with $p_{\mathrm{HCl}} \mathrm{S}$ as shown in Table 3 .

$$
\begin{aligned}
& \operatorname{DPn} a v=\left\{y\left(\operatorname{DPn} p-\mathrm{DPn} o^{\prime}\right)+y^{\prime}\left(\mathrm{DPn} o-\mathrm{DPn} o^{\prime}\right)\right. \\
& + \text { DPno' }\} / 100
\end{aligned}
$$

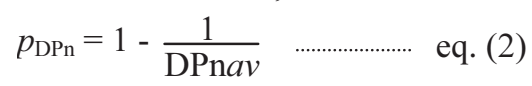

Fig. 6 Plots of number of polymer chains in the precipitates $(N p)$ prepared in (a) DCE, (b) $2 \%-\mathrm{NB}$ and (c) $\mathrm{CH}$ as a function of polymerization time.

where DPn $p$ : DPn of the precipitated polymers, DPno: DPn of the compounds recovered from solution, DPno': DPn of the compounds lost during washing with methanol, $y$ : yield percentage of the precipitated polymers, $y^{\prime}$ : yield percentage of the compounds dissolved in solution.

The DPno' in eq. (1) was assumed as 1.5. The $p_{\mathrm{HCl}} \mathrm{S}$ in $\mathrm{DCE}$ and $\mathrm{CH}$ are bigger than $p_{\mathrm{DPn}} \mathrm{s}$, and this indicates that $\mathrm{HCl}$ is not left in the solution. On the contrary, the $p_{\mathrm{HCl}}$ in $2 \%$-NB is smaller than the $p_{\mathrm{DPn}}$. The content of $\mathrm{HCl}$ left in the solution estimated from the difference between the $p_{\mathrm{HCl}}$ and the $p_{\mathrm{DPn}}$ is $0.42 \mathrm{~mol} \cdot \mathrm{L}^{-1}$. This higher solubility of $\mathrm{HCl}$ prevents the further progress of the reaction in $2 \%$-NB. Moreover, NB is a weak base and it deactivates $\mathrm{AlCl}_{3}$ by the coordination leading to the termination of the reaction [11]. In the case of $\mathrm{CH}$, $\mathrm{AlCl}_{3}$ and the complex of IPC-AlCl 3 are hardly dissolved. Additionally, the Ds is very low as described before. The precipitated dimers do not possess enough high mobility for the further polymerization in the precipitates.

The precipitation polymerization behavior can be understood as follows. When the DPn of oligomers 
Table 3 Extent of reaction calculated from titration data and DPn ${ }^{\text {a }}$

\begin{tabular}{cccc}
\hline \multirow{2}{*}{ Solvent $^{\mathrm{b}}$} & \multicolumn{2}{c}{$\begin{array}{c}\text { Extent of reaction } \\
\end{array}$} & \multicolumn{2}{c}{$(p)$} & $\begin{array}{c}\text { Content of } \mathrm{HCl} \text { left in } \\
\text { solution }^{\mathrm{e}}\left(\mathrm{mol} \cdot \mathrm{L}^{-1}\right)\end{array}$ \\
\cline { 2 - 3 }${ }^{\mathrm{c}}$ & $p_{\mathrm{HCl}}{ }^{\mathrm{d}}$ & \\
\hline $2 \%-\mathrm{NB}$ & 0.34 & 0.94 & 0.42 \\
$\mathrm{DCE}$ & 1.10 & 0.98 & 0 \\
$\mathrm{CH}$ & 0.36 & 0.35 & 0 \\
\hline
\end{tabular}

${ }^{a}$ Polymerizations were carried out for 8 hours.

${ }^{\mathrm{b}}$ Solvent codes are shown in Table 1.

${ }^{\mathrm{c}}$ Data at $25^{\circ} \mathrm{C}$ are cited from ref. 11.

${ }^{d}$ estimated from the results of $\mathrm{HCl}$ titration.

e calculated according to eqs. (1) and (2).

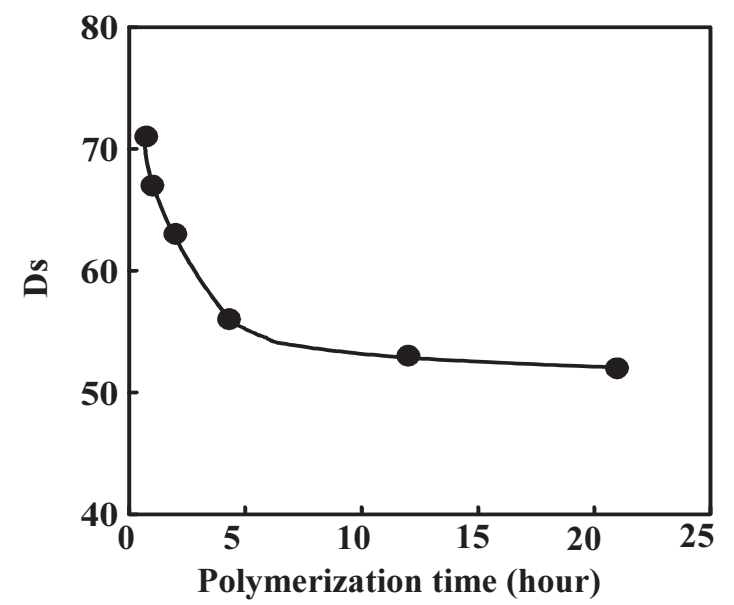

Fig. 7 Plot of DS of PDCE as a function of polymerization time.

exceeds a critical value, the oligomers are precipitated to form the gels of the complex with $\mathrm{AlCl}_{3}$ at the early stage of polymerization. In DCE, the swollen oligomer gels are formed in which any regular structures do not exist. The oligomers are continuously precipitated from the solution by the oligomerization, leading to increase of the yield. Both the oligomers and the monomers dissolved in the solution penetrate gradually into the precipitates to compensate the imbalance of stoichiometry between two functional groups, and the reaction proceeds with eliminating by-produced $\mathrm{HCl}$ in the precipitates. The reaction between the precipitated oligomers also occurs due to the enough high mobility of the oligomers. As a result, high molecular weight polymers can be synthesized even in the precipitates. When the polymerization is carried out in $2 \%-\mathrm{NB}$, the highly swollen precipitates of the oligomers are also formed in which the oligomers possess enough high mobility to polymerize. However, the solubility of $\mathrm{HCl}$ into the solvent is high and $\mathrm{AlCl}_{3}$ is deactivated by the

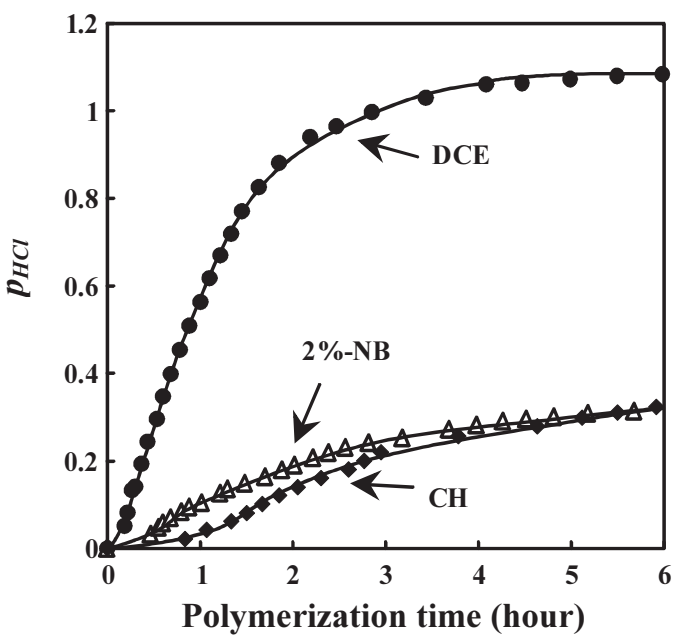

Fig. 8 Polymerization time dependencies of extent of reaction $\left(p_{H C l}\right)$ calculated based on the quantity of evolved $\mathrm{HCl}$ gas during polymerization in various solvents.

coordination of NB. Therefore, the reaction is terminated in the precipitates and high molecular weight polymer cannot be synthesized in $2 \%$-NB. The precipitation occurs more readily in $\mathrm{CH}$ due to the lower solubility of the oligomers. The resulting precipitates comprised of the dimers are not swollen in this case, and thereby it is very difficult for monomer to penetrate into the precipitates and for $\mathrm{HCl}$ to come out from the precipitates. The dimers do not possess enough high mobility in the precipitates. Additionally, $\mathrm{AlCl}_{3}$ is insoluble in $\mathrm{CH}$. Hence, the further reaction cannot proceed in the precipitates. The solvents having high miscibility to catalyst and the polymers, low solubility of $\mathrm{HCl}$ gas, and no basicity are necessary for making high molecular weight polymers via the precipitation polymerization.

\section{Conclusion}

The solvent influences significantly the behavior of the precipitation polymerization of PEK. In DCE, the oligomers are precipitated as a form of the complex with $\mathrm{AlCl}_{3}$ at the early stage of polymerization. The precipitates of the oligomers are well swollen and they do not possess any short-range regular structure. Oligomers are continuously supplied to the gel from the solution by the oligomerization reaction. Both the oligomers and the monomers dissolved in the solution penetrate gradually into the precipitates to compensate the imbalance of the stoichiometry between two functional groups. The reaction progresses even in the precipitates with eliminating by-produced $\mathrm{HCl}$ and high molecular weight polymers are finally synthesized even 
in the precipitates. The polymerization behavior in the precipitates is like the solution polymerization rather than the solid-state polymerization. The solvents having high miscibility to catalyst and the polymers, low solubility of $\mathrm{HCl}$ gas, and no basicity are necessary for making high molecular weight polymers via the precipitation polymerization.

\section{References}

1. M. J. Mullins, and E. P. Woo, J. Macromol. Sci. Rev. Macromol. Chem. Phys., C27, 313 (1987).

2. M. J. Zolotukhin, N. G. Gileva, S. N. Salazkin, Y. A. Sangalov, Y. V. Genin, and V. S. Sutanova, Polym. Sci. U.S.S.R., 31, 2748 (1989).

3. Y. Sakaguchi, M. Tokai, and Y. Kato, Polymer, 34, 1512 (1993).

4. M. G. Zolotukhin, M. Dosiere, C. Fougnies, D. Villers, N. G. Gileva, and A. A. Fatykhov, Polymer, 36, 3575 (1995).
5. M. G. Zolotukhin, D. R. Rueda, F. J. B. Calleja, M. Bruix, M. E. Cagiao, A. Bulai, N. G. Gileva, Macromol Chem Phys, 198, 1131 (1997).

6. M. G. Zolotukhin, D. R. Rueda, F. J. B. Calleja, M. E. Cagiao, M. Bruix, F. A. Sedova, and N. G. Gileva, Polymer, 38, 1471 (1997).

7. Y. Sakaguchi, K. Kimura, M. Omori, and Y. Yamashita, Polymer Journal, 34, 219 (2002).

8. H. Takeuchi, M. Kakimoto, and Y. Imai, J. Polym. Soc. : Part A : Polym. Chem., 40, 2729 (2002).

9. G. A. Olar, "Friedel-Crafts and Related Reactions", Vol. 3, Interscience Publishers a division of John Wiley \& Sons. New York, Chapter 31, pp.4-5, 546549 (1963).

10. S. I. Troyanov, Zh Neorg Khim, 37, 266 (1992).

11. P. H. Gore, Chem Rev, 55, 229 (1995).

12. P. G. T. Fogg, and W. Gerrard, "Solubility of gases in liquids : a critical evaluation of gas/liquid system in theory and practices", John Wiley, Chapter 9, pp.187-217 (1991). 